\title{
The Role of Universities in Promoting Scholarly Work in the Emerging Open Access World
}

\author{
Joseph E. Steinmetz, Chancellor \\ University of Arkansas
}

$\mathrm{I}$

have been in higher education and at universities as a member of the faculty or an administrator for over 35 years. I can say with some confidence that during these 35 years, I have never seen a period of time when there has been more volatility and change in our institutions of higher education as there is currently. These changes include our financial models for operating the university, well-justified pressures to enhance student success as measured by increased student retention and graduation rates, expectations for greater research productivity, and a growing role in community outreach and engagement as well as regional and state economic development. As always, we are expected to provide a significant benefit for society in general as well as a direct benefit for the individual students who choose to attend our institutions. Superimposed on this is a rapidly changing technological world that while enabling new and exciting opportunities, also requires our students, faculty, staff and administrators to think in new ways to maximize the benefits that can be gained from these advances.

The world of open access is one of these new, emerging movements. There is no question that the open access movement has the potential to break down barriers that may impede the spread of knowledge and innovation. Yet I believe we still find ourselves negotiating some of the same old obstacles to change. In the words of Walter Lippmann, "we have changed our environment faster than we can change ourselves." (Lippmann, 1922). Here, I write briefly on what I believe is the role of our universities in promoting scholarly work in an emerging open access world. I will cover how open access research and scholarship generally fits in with our larger research and discovery mission, and what obstacles need to be overcome to move it forward.
Although I suspect most everyone has some grasp of the conversation about open access, I think it's worth quickly reviewing some of the factors driving this movement, particularly on campuses like mine. On our campus, as on many others, discussions about open access are happening on two different fronts. First, open access can refer to placing published data in a public archive that can be accessed by others. Second, many at the University of Arkansas as well as at other universities are also interested in open access publishing, a form of publishing that is largely free or lower cost than traditional form sof publication and also has the potential to enhance access to knowledge and discoveries. Both of these discussions may be important for the future of research and discovery. 


\section{A Current Issue: Greater Financial Pressures at our Research Universities}

Before delving further into the topics of open access data and open access publishing, I think it is important to point out at least one major factor that seems to dominate our discussions at public universities these days - that is, the major change in how our universities will be funded in the future. Indeed, no conversation about changes in higher education, particularly at public universities, can occur without reference to how funding our public universities has changed over the years-it is the context in which we find ourselves.

I saw some data recently that I think will put this in context. Between 1961 and 2015, the Consumer Price Index increased $696 \%$, which is not a particularly shocking number. Over the same time, however, the Higher Education Price Index (HEPI), increased a whopping $1,124 \%$. The HEPI captures the major cost drivers in higher education. Importantly, as the HEPI inflation rapidly outpaced the CPI, over the same period of time we witnessed a drastic reduction in the support provided to universities by our states across the country. The University of Arkansas exemplifies this national trend. As late as 1999 at the U of A roughly $70 \%$ of our operating funds came from a state allocation. The remaining $30 \%$ came from tuition and a few other sources of revenue. Now this situation has more than flipped-our state support now makes up about $17 \%$ of our operating funds with student tuition and a few other sources of revenue (such as private donations) making up the balance of our operating budget. And we have it relatively good in Arkansas as our state commitment is higher than many other states; I know of several public research universities where the state contribution as a percentage of support is in the single digits and declining.

Another fact to consider is that virtually all public universities subsidize their research mission with general funds-Indirect Cost Recovery (ICR) is not enough to cover expenses related to the research infrastructure that is necessary to conduct research. I have often found it difficult to get faculty to understand this point; many are convinced that the ICRs they generate cover all research expenses. And, at many institutions this situation is exacerbated by the fact that some ICR funds are distributed back to individual investigators thus decreasing funds available to invest in necessary university-wide research infrastructure. Given that our general fund budget these days comes largely from student tuition, this means that at virtually all public universities, student tuition and not state funds are being used to subsidize research and discovery. And, as the availability of state funds shrink even further we are faced with growing pressure to do more with less. This sometimes forces us to make extremely difficult decisions on what we fund. And sometimes, this becomes a binary choice: Do we use our resources to fund student instruction or to fund research and discovery? Both are important at a research university. Since over the last several years we have raised tuition dramatically, a growing pressure has mounted to fund activities that support student success. At public universities students are the source of much of our operating funds. This means 
that relatively fewer funds are available to support research and discovery. This financial model is clearly not sustainable for operating our public research universities.

So, what does all this have to do with open access? Our university budgets are stretched like never before making it difficult to commit to any new initiatives beyond the bare minimum, and this includes commitments to underwrite open access. And one place where financial pressures are really being felt is within our University Libraries. Libraries are key to open access discussions as their expertise in managing archives and access to publications is important. Libraries are feeling the pinch of reduced support and funding, particularly related to research and scholarship. From their perspective the sharing of research and materials across institutions and between scholars makes perfect sense. And this discussion is not limited to research and scholarship. Many universities are also discussing ways to share teaching resources in an open access environment as well.

Fiscal Challenges Aside Why is Open Access for Data Important?

While fiscal issues are important, money should not be the only factor driving discussions about open access. There is a compelling case for open access: open access to data could be good for research and discovery. Perhaps the poster child for the success of open access data is the Human Genome Project, which is regarded as a model for how open data can be used for public good rather than private gain. An oft-cited study by an MIT professor, Heidi Williams, found that "nearly 30\% more genetic diagnostic tests emerged from sequenced genes that were always in the public domain, compared to genes that were temporarily withheld from the public with intellectual property rights after being sequenced by a private firm." https://sparcopen.org/impactstory/human-genome-project/

There are a number of other successes that resulted from this project, both economic and technological, which I will not review here. Perhaps most important for our discussion here, this project, as well as several others inspired by it, influenced the White House Office of Science and Technology Policy to issue a directive in 2013 requiring taxpayerfunded research to be made freely available to the general public. https://sparcopen.org/news/2017/fastrreintroduction/ The goal was to accelerate scientific discovery and innovation. And this has subsequently led to the bipartisan Fair Access to Science and Technology Research Act, or FASTR, which is making its way through the House and Senate, as of this writing. FASTR would require agencies with annual extramural research budgets of $\$ 100$ million or more to provide the public with online access to research manuscripts. This is driving a lot of the conversation around data open access on the federal level.

\section{Why is Open Access Publishing Important?}

The second open access issue that is being discussed on my campus as well as many other campuses is open access publishing. Much of this discussion is centered on the increasingly high cost of publishing research in a time when resources are increasingly tight. Consider 
this: an institutional subscription to Brain Research, a journal in which I published my behavioral neuroscience research in the past, is currently $\$ 12,113$ a year. It is published by Elsevier. I note that this not a particularly high price for an Elsevier publication, which can run in the tens of thousands of dollars. As the publisher of a self-reported 420,000 articles a year, Elsevier has been the topic of conversation over the last several years. For example, in a recent book, The Open Revolution (which can be downloaded free as a PDF, incidentally), Rufus Pollock has this to say about Elsevier:

"Cleverly, Elsevier has inserted itself as an intermediary - a platform - between academic authors and academic readers, controlling many journals which are mini-monopolies in their fields. Increasingly, publishers like Elsevier are exploiting the very academic community they should serve, using monopoly power to hike prices year after year. Meanwhile, they depend for their content and much of the editorial work on the same scholars, who offer their publicly-funded labour (and their copyrights) for free. And since academics have little choice, because they are obliged to publish in "reputable journals", they are held to ransom as surely as the libraries that are obliged to subscribe to the journals" (Pollock, 2018, Pg. 14).

Our Dean of Libraries at the University of Arkansas, Ms. Carolyn Henderson Allen, estimates the cost of journals has gone up roughly $8-13 \%$ a year over the last 10-15 years, depending on the journal. This has created a difficult situation. Given that these costs are rising far faster than funding, libraries are being forced to make agonizing decisions about to which journals subscriptions should be maintained. Obviously, this is difficulta variety of journals in a variety of areas are critical for our faculty and students to stay abreast of the latest developments in their respective fields. We anticipate some difficult conversations with faculty as deeper cuts must be made in the coming years, which can seriously injure our larger research mission. I bring this all up to emphasize the fact that there are external and internal pressures to move toward a more open publishing model that benefits our researchers and scholars.

Obstacles to Open Access on

\section{Campuses}

There are obstacles on our campuses to open access to data and publishing and also some limitations that are related to a more general commitment wehave made to research and scholarship on campus. I present some of these obstacles here. These obstacles can be divided into two broad categories. The first category could be described as philosophical or cultural while the second category can be described as technological (which includes, of course, financial considerations). I start with the philosophical/ cultural obstacles related to creating and maintaining an open access system for data.

Any open access effort must have the buy-in and the backing of the community of researchers who generate the data. When I was starting out as a researcher, I 
would have been reluctant to share my data. I had a strong sense of ownership of my work and would not have been comfortable sharing my data before I had time to properly work through it completely and exhaustively, which of course can take years. While some versions of FASTR seeks to extend the embargo period from six months to one year, that is still not a long time, especially for researchers who continue to scrutinize, mine and find new ways to analyze and think about published data for many years. For some there is a worry that their data set may be used as the basis of someone else's research, something that may be easier if the complete published data set is readily available to be mined by someone else. The fear I have heard expressed is that investigators, especially newer investigators, are vulnerable to larger and often better funded labs that could throw more money and people at a research problem that originates with the original data set that is published. By the way, I tend to hear this argument more often from senior faculty on behalf of more junior faculty than I do from my more junior colleagues. So, it seems paramount that we make our faculty comfortable with the idea that data sharing does not necessarily mean that someone else is going to swoop in and get famous from their work. I return to an earlier point I made: we should be arguing that science and discovery would proceed faster if data sharing was commonplace. And, perhaps collaboration would become more prevalent. These are both good things, not bad things, for research and discovery.

I am convinced that a very important way we will be able to sustain our research mission at universities is to develop more robust partnerships with the private sector. A number of businesses and industries have reduced their research and development efforts over the years and are increasingly more dependent on universities for this function. Federal funding for research has, for the most part, been flat the last few years and state support for research is virtually nonexistent in most states. Furthermore, it is difficult to predict the future of federal support for research. For example, increasing the federal deficit tends to hurt research eventually as this source of discretionary funding becomes less of a priority. All told, this means that there is a decreasing amount of money available from federal grants and university budgets to support research.

At a campus like ours, where we are determined to grow our research volume, we believe that we are going to have to diversify our research funding sources, and that means creating more partnerships with companies willing to support research, both basic and applied. We are pursuing this aggressively. While this will require a blending of research agendas, more than likely private industry is not going to be interested in feeding open access repositories and databases. Perhaps bits and pieces can be made public, but by and large they will have a proprietary interest in keeping some of the research private. And, again, if we are really interested in advancing science, discovery, research and scholarship, we should be advocating for open access to all data, not just those data sets generated with federal dollars. This will prove to be challenging for industryrelated research. 
There are also philosophical and cultural obstacles to open access publishing. Perhaps the biggest obstacle to publishing in open access journals is that they don't have the same prestige as long-established traditional publications. In part, this has enabled established publishers to maintain their stranglehold on scientific publishing. And, it is difficult to blame faculty for clinging to the traditional model of publishing when annual performance reviews and promotion and tenure are at stake. Many questions are raised by individual faculty and evaluation committees about open access publishing. Will individuals be punished for publishing in open access places instead of more traditional (and hence more reputable) publications? Will it harm their efforts to get tenured and be promoted? And when it comes to open access publication journals, how can rigor be ensured? How can the quality of publication be evaluated? At the very least, it is clear that new metrics need to be worked out to evaluate open access publishing. That is, new ways of measuring impact, which is what these kinds of evaluations are supposed to be all about. For some fields, this process is already being thought through.

There is a second category of obstacles, which are technological and, by extension, financial, which can impact open access efforts. Just as finances are driving the push for open access research in the libraries, they are also limiting the speed of its spread and the shape it can take. Creating and maintaining an open access environment means making strategic investments in the hardware and software needed to store, access, discover and share information. It also means ensuring networking capabilities, interoperability between colleges and campuses, both in state and out, as well as integration with national resources. It also means making allocations for maintenance, technical support, and the overall security of the system so that you have a firewall between what you want to share and what you don't want to share. This last point is extremely important if you are working with private industry or doing classified research. You do not want someone to sneak into your system and swipe the fruits of your efforts or severely damage your partnerships you may have established with other researchers or with industry. Security of theopen access system is a very real concern.

All of the things I just listed above require allocations of time, money, training, and people. I refer you back to my earlier discussion about dwindling resources: this means making hard choices about how we spend limited resources. Recently, staff from our Office of the Chief Information Officer and High-Performance Computing Center made a pitch for investments of half a million dollars a year for the next four years in campus computing infrastructure. This is a relatively big request these days on our campus given the tremendous pressures on our budget from a number of other equally important projects. This proposal though has a lot of merit. Data-driven research has emerged in virtually every field and our computing center now serves an ever more diverse body of users. Here on our campus genetics researchers run small bits of code on hundreds of nodes and create thousands of small files to be 
analyzed. Geoscientists build predictive models from terabytes or petabytes of data to build increasingly higher resolution predictive models. Large models of complex materials are created by engineers and physicists working together. Sociologists and geographers work with economists to build complex models of human behavior using data sources from around the world. They need the university to provide the computing backbone for these and a lot of other activities.

But in the end what does this $\$ 2 \mathrm{M}$ investment buy us as an institution? The honest answer is the bare minimum to serve our faculty's growing needs and, we hope, keep us competitive for federal grants. This minimum investment allows us to update our computing resources and to provide additional computational support for researchers. If we really wanted to get ahead of the curve, then our computing staff estimate we would need to make investments of an additional million dollars a year for the next four years for a total spend of $\$ 6 \mathrm{M}$. This spend is in addition to any funds that we would need to invest in open access data and publishing systems. That is, resources needed to advance open access research are in direct competition with critical resources needed to maintain, not to mention enhance, our basic research mission.

\section{A Role for the University}

What is the university's role in all of this? First and foremost, any discussion of promoting open access scholarship should occur within a context of campus priorities. For example, here at the University of Arkansas we completed a comprehensive institutional planning process from which eight guiding priorities were developed and articulated. https://www.uark.edu/strategicplan/index.php\#guiding-priorities.

While promoting open access research and scholarship is not a defined priority per se, it is a factor in some of the general categories that did emerge in areas like "Building a Collaborative and Innovative Campus," "Enhancing our Research and Discovery Mission," and "Investing in Faculty Excellence." More immediate concerns were identified, such as improving our competitiveness for federal funding and preserving our Carnegie Research 1 status. And for us, expanding our research capabilities and infrastructure has become a regional priority, as evidence by the Northwest Arkansas Council identifying research at the university as a major driver of further economic development in the region. http://content.nwacc.edu/publicrelations /presidentsoffice/Goals\%20and $\% 20$ Objec tives.pdf

To jump start research we created the Chancellor's Discovery, Creativity, Innovation and Collaboration Fund - or the Chancellor's Fund for short. We have initially budgeted $\$ 1 \mathrm{M}$ annually to ensure high interest and participation. A year ago, we received 75 proposals and awarded 10 research grants to 30 faculty. This spring, we received 93 proposals of which we will fund 10-12. While it's too early to determine whether this program will lead to increased research funding, we can say that it is already accomplishing one of our main goals, which is to enhance collaboration on cam pus. Of the 93 proposals we received, 290 faculty were listed as Principal Investigators or co-PI's-faculty are 
exchanging ideas, taking risks, and forging new partnerships. That's exactly what we wanted to happen. If those partnerships are funded and sustained through extramural funding after the initial award runs out, that is a step toward broadening our research and discovery efforts. And if those partnerships form the basis of a working partnership that extends well into the future, that is great, too. The point is, we made this investment as a result of our campus prioritizing collaborative and innovative research.

What else should universities be doing to promote open access? It's increasingly clear that the traditional model of academic publishing is not sustainable from a cost perspective and there is much to be gained by breaking down paywalls that are devastating library budgets and restricting access to information, particularly information that is publicly funded. I believe universities have a role to play in overcoming the bias against open access journals. And, the university has a clear role in promoting open access for datait is good for research and discovery.

First and foremost, we must rethink our current system of tenure and promotion-it's outdated. We are using the same approach and almost the same metrics for the last century. We must figure out how to measure the impact of someone's work in an age that values open access, collaboration, and more links with industry, among other things. We need to think well beyond counting books, journal articles and grant dollars to new ways to measure impact, including ways to measure the impact of publishing in open access journals. Doing so will help alleviate some tenure and promotion fears that are related to publishing in open access sources. If faculty don't see open publishing as injurious to their career, they are more likely to embrace it, and advocate for investing in the hardware, software and expertise needed to support it. And, until new tenure and promotion norms are established nationwide that make open publishing and data sharing more attractive, there will be little momentum on individual campuses to move in this direction. In short, this is not an issue that can be resolved by an individual campus.

Second, we also have to encourage our faculty to embrace an open access data environment. Even though I have heard some of our faculty express a fear of sharing their data widely, I am not sure this fear is actually well-founded. But nevertheless, it needs to be dealt with. Perhaps the use of data sets by others should be a measure of impact-like counting citations is for traditional journals. And, I am sure we can devise ways to require an acknowledgement of data bases used in the same way we require referencing and citations.

A final thing for universities to consider: we also need to identify where cost efficiencies may exist, particularly in building a state-of-the-art open access system. Partnerships with others might go a long way to realize these efficiencies. The University of Arkansas is part of a system that includes several 2-year and 4year institutions. Collectively, we have used the system to leverage lower costs in things like our Learning Management System and, more recently, a common Enterprise Resource Planning system. I 
spent time at Indiana University and Ohio State University and also saw shared systems work effectively for the Big Ten conference schools through the Committee on Institution Cooperation (now called the Big Ten Academic Alliance). An example of this is how a variety of lesser-taught languages are shared across these institutions. Perhaps these are models for building an open access system across universities - that is, universities sharing expenses and system development. In fact, this kind of shared model may be useful in a number of areas as we try to find more innovative ways to fund and operate our universities. We should be collaborators, not com petitors.

\section{References}

Lippmann, Walter (1922). Public Opinion, London: George Allen \& Unwin, Ltd. Mitchell, B.C. \& King, W.J. (2018). How to Run a College, Baltimore: Johns Hopkins University Press.

Pollock, R. (2018). The Open Revolution, A/E/T/ Press. Available for download here: https://openrevolution.net/media/open-revolution.pdf 